\title{
Risks and Benefits of Sodium Polystyrene Sulfonate for Hyperkalemia in Patients on Maintenance Hemodialysis
}

\author{
Teruko Nakamura $^{1} \cdot$ Taisei Fujisaki $^{1} \cdot$ Motoaki Miyazono $^{2} \cdot$ Maki Yoshihara $^{2} \cdot$ Hiroshi Jinnouchi $^{3} \cdot$ Kenichi Fukunari $^{4}$. \\ Yuki Awanami ${ }^{4} \cdot$ Yuki lkeda $^{4} \cdot$ Kohei Hashimoto ${ }^{2} \cdot$ Masatora Yamasaki $^{2} \cdot$ Yasunori Nonaka $^{2} \cdot$ Makoto Fukuda $^{2}$. \\ Tomoya Kishi $^{2} \cdot$ Yuji lkeda ${ }^{2}$ (i)
}

Published online: 10 August 2018

(c) The Author(s) 2018

\begin{abstract}
Background Concerns about sodium overload when using sodium polystyrene sulfonate (Na-resin) as an ion-exchange resin for the treatment of hyperkalemia led our institution to gradually shift to the use of calcium polystyrene sulfonate (Ca-resin). However, as serum potassium levels were insufficiently controlled and patients experienced constipation, we returned to using Na-resin and observed better results than previously.

Objective As few papers have examined the potassium adsorption ability of Ca-resin compared with Na-resin, we investigated this issue within our institution.

Methods We studied potassium adsorption in patients who switched from Ca-resin to an equivalent amount of Na-resin (change group). We also investigated the incidence of sodium loading with Na-resin, including in patients newly commencing Na-resin treatment (new start group).

Results Mean ( \pm standard deviation) serum potassium levels decreased significantly, from $5.5 \pm 0.6$ to $4.9 \pm 0.6 \mathrm{mEq} / \mathrm{l}$ in the change group and from $5.9 \pm 0.4$ to $4.7 \pm 0.6 \mathrm{mEq} / \mathrm{l}$ in the new start group. No changes were observed in blood pressure, weight gain or serum sodium levels in the change group, but serum sodium levels in the new start group increased significantly, from $137.4 \pm 2.3$ to $139.0 \pm 2.5 \mathrm{mEq} / 1$, although they remained within the normal range.

Conclusions Our results indicate that Na-resin exhibited an advantage in treating hyperkalemia when used in small amounts. However, when prescribing an ion-exchange resin at a higher dose, physicians should select the type and amount of resin according to the sodium and/or calcium load in each case.
\end{abstract}

Yuji Ikeda

ikedayuu@cc.saga-u.ac.jp

Fujisaki Hospital, Sakaemachi, Karatsu, Saga, Japan

2 Department of Internal Medicine, Saga University Faculty of Medicine, 5-1-1 Nabeshima, Saga, Saga 849-8501, Japan

3 Jin-nouchi Clinic, Shingo-Honmachi 24-3, Saga, Saga, Japan

4 Department of Nephrology, Sasebo Kyosai Hospital, Shimanji-cho 10-17, Sasebo, Nagasaki, Japan

\section{Key Points}

In the treatment of hyperkalemia, the potassium adsorption ability of sodium polystyrene sulfonate (Na-resin) is slightly stronger than that of calcium polystyrene sulfonate (Ca-resin).

Treatment with Na-resin is also expected to improve acidosis.

Na-resin exhibits an advantage over Ca-resin because a smaller amount is sufficient to treat hyperkalemia (5-15 g/day); however, if a higher-dose ion-exchange resin is required, physicians should select the type and amount of resin according to the sodium and/or calcium load. 


\section{Introduction}

Hyperkalemia may cause fatal arrhythmia in patients undergoing maintenance hemodialysis. An overview of regular dialysis treatment in Japan found that, in 2013, of all deaths in Japanese patients receiving hemodialysis, 775 (2.6\%) were attributable to hyperkalemia or sudden death [1]. In the past 20 years, the rate of death due to hyperkalemia or sudden death was constant at $4.3 \pm 0.8 \%$. In the majority of patients receiving hemodialysis, it is possible to avoid death from hyperkalemia with dietary therapy and adequate hemodialysis. However, some patients require treatment with an ion-exchange resin to prevent hyperkalemia.

Although a promising new therapy for hyperkalemia has recently been developed, it is not yet available in Japan [2, $3]$. Two types of ion-exchange resins are currently available in Japan for the treatment of hyperkalemia: sodium polystyrene sulfonate (Na-resin) was first sold in 1971, and calcium polystyrene sulfonate (Ca-resin) was released in 1975 to prevent the sodium loading caused by Na-resin and gradually became widespread as a treatment for hyperkalemia. However, we felt that serum K levels were insufficiently controlled with Ca-resin compared with Na-resin, and our patients had increasingly reported experiencing constipation. Upon returning to Na-resin, we were able to adjust serum $\mathrm{K}$ levels to lower values than previously.

Few papers have investigated the potassium adsorption ability of Ca-resin compared with that of Na-resin. Therefore, we investigated this issue among patients who switched from Ca-resin to an equivalent amount of Na-resin. Furthermore, in patients with oliguria or anuria receiving dialysis, the sodium load is expected to be reflected in an increase in sodium in the fluid, thus resulting in weight gain and increased blood pressure. Therefore, we also investigated the incidence of sodium loading in study participants, including those newly commencing Na-resin treatment.

\section{Methods}

This was a retrospective observational study. We included patients who switched from Ca-resin to an equivalent amount of Na-resin (change group) and patients who commenced treatment with Na-resin (new start group) between October 2009 and October 2012 at our own and affiliated hospitals. Patients received Na-resin after meals. In the change group, the time and frequency of taking the resins did not alter. Dialysis was performed at a blood flow rate of $200 \mathrm{ml} / \mathrm{min}$ and a dialysate potassium concentration of
$2.0 \mathrm{mEq} / \mathrm{l}$, which is a standard dialysis setting in Japan. We excluded patients whose dialysis conditions changed during the study period. At our hospital, all patients receive education on potassium-restricted diets when dialysis is introduced, but no additional education was given during this observation period. No other diet-related interventions were undertaken, nor were any changes made to the injected and oral medications before or after the start of Na-resin.

Patients were monitored for 4 weeks before and after the administration of Na-resin. Blood samples were collected before dialysis at the first session of each week. The parameters were compared by averaging four data points obtained over the 4-week period. The following parameters were measured: $\mathrm{K}, \mathrm{Na}, \mathrm{Ca}, \mathrm{Cl}, \mathrm{P}$, estimated $\mathrm{HCO}_{3}^{-}\left(\mathrm{eHCO}_{3}^{-}=\mathrm{Na}-\mathrm{Cl}-\mathrm{P}-7\right)$ [4], blood pressure at the start of dialysis, weight gain $(\%)=$ (weight before hemodialysis - weight after hemodialysis at the last visit)/ dry weight $\times 100$, changes in medications (antihypertensive agents, laxative agents) and complaints of constipation. The serum Ca level was adjusted according to Payne's formula [5]: serum $\mathrm{Ca}^{+}$(4-serum Alb).

Continuous variables were assessed using Wilcoxon's signed-rank test with the Excel 2011 software package (Microsoft, Redmond, WA, USA) with the add-in software plugin Statcel 2 (OMS, Saitama, Japan). Dialysis conditions are presented as medians (minimum-maximum), and other data are presented as mean \pm standard deviation. For all comparisons, differences at a $p$ value $<0.05$ were considered statistically significant.

\section{Results}

Table 1 presents the background characteristics of enrolled patients (11 patients in the change group and 29 patients in the new start group).

Tables 2 and 3 show the data for the change group and the new start group, respectively. On average, the dose of resin was $8.2 \pm 2.6 \mathrm{~g} /$ day in the change group and $8.7 \pm 5.5 \mathrm{~g} /$ day in the new start group.

Serum K levels decreased significantly from $5.5 \pm 0.6$ to $4.9 \pm 0.6 \mathrm{mEq} / \mathrm{l}$ in the change group and from $5.9 \pm 0.4$ to $4.7 \pm 0.6 \mathrm{mEq} / \mathrm{l}$ in the new start group.

No changes were observed in blood pressure, weight gain or serum $\mathrm{Na}$ levels in the change group. Serum $\mathrm{Na}$ levels in the new start group increased significantly from $137.4 \pm 2.3$ to $139.0 \pm 2.5 \mathrm{mEq} / \mathrm{l}$, although they remained within the normal range. Antihypertensive agents were newly required in two cases in the new start group.

The rate at which constipation was reported and laxatives used did not change after switching from $\mathrm{Ca}$-resin to $\mathrm{Na}$-resin in the change group. Conversely, three patients in 
Table 1 Patient characteristics

\begin{tabular}{|c|c|c|}
\hline Characteristics & Change group & New start group \\
\hline Age (years) ${ }^{\mathrm{a}}$ & $68.9 \pm 12.0$ & $66.3 \pm 10.6$ \\
\hline \multicolumn{3}{|l|}{ Sex } \\
\hline Male & 5 & 16 \\
\hline Female & 6 & 13 \\
\hline Hemodialysis history (year) $^{\mathrm{b}}$ & $6.8 \pm 6.4(2.6-25.2)$ & $7.0 \pm 7.5(0.2-31.9)$ \\
\hline \multicolumn{3}{|l|}{ Primary disease } \\
\hline Chronic glomerulonephritis & 4 & 13 \\
\hline Diabetic nephropathy & 3 & 10 \\
\hline Nephrosclerosis & 1 & 2 \\
\hline Rapidly progressive glomerulonephritis & 0 & 1 \\
\hline Gout & 0 & 1 \\
\hline Pyelonephritis & 1 & 0 \\
\hline Unknown & 2 & 2 \\
\hline \multicolumn{3}{|l|}{ Dialysis conditions } \\
\hline Number of times per week & 3 & 3 \\
\hline Treatment time $(h)^{c}$ & $4.0(4-4.5)$ & $4.0(3.5-5.0)$ \\
\hline Quantity blood $(\mathrm{ml} / \mathrm{min})^{\mathrm{c}}$ & $200(200-250)$ & $200(200-200)$ \\
\hline \multicolumn{3}{|l|}{ Dialyzer } \\
\hline Membrane area $\left(\mathrm{cm}^{2}\right)^{\mathrm{c}}$ & $1.9(1-2.1)$ & $1.6(1-2.1)$ \\
\hline \multicolumn{3}{|l|}{ Membrane material } \\
\hline PS & 4 & 13 \\
\hline PES & 4 & 10 \\
\hline PEPA & 1 & 3 \\
\hline PMMA & 2 & 2 \\
\hline CTA & & 1 \\
\hline
\end{tabular}

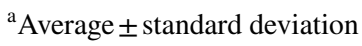

${ }^{\mathrm{b}}$ Average \pm standard deviation (minimum-maximum)

${ }^{\mathrm{c}}$ Median (minimum-maximum)

$C T A$ cellulose triacetate, $P E S$ polyethersulfone, PEPA polyester-based polymer alloy, PMMA polymethylmethacrylate, $P S$ polysulfone

Table 2 Changes in parameters: change group

\begin{tabular}{lccc}
\hline Parameter & \multicolumn{1}{c}{ Ca-resin } & Na-resin & $p$ value \\
\hline $\mathrm{SBP}(\mathrm{mmHg})$ & $152.4 \pm 22.8$ & $152.2 \pm 19.4$ & 0.929 \\
$\mathrm{DBP}(\mathrm{mmHg})$ & $78.4 \pm 13.7$ & $83.4 \pm 20.4$ & 0.878 \\
$\Delta \mathrm{Weight}^{\mathrm{a}}(\%)$ & $4.7 \pm 2.1$ & $4.7 \pm 1.9$ & 0.859 \\
$\mathrm{Na}(\mathrm{mEq} / \mathrm{l})$ & $138.1 \pm 3.3$ & $138.6 \pm 2.9$ & 0.445 \\
$\mathrm{~K}(\mathrm{mEq} / \mathrm{l})$ & $5.5 \pm 0.6$ & $4.9 \pm 0.6$ & $<0.05$ \\
$\mathrm{Cl}(\mathrm{mEq} / \mathrm{l})$ & $104.4 \pm 4.4$ & $102.6 \pm 3.6$ & 0.083 \\
$\mathrm{Ca}^{\mathrm{b}}(\mathrm{mg} / \mathrm{dl})$ & $9.1 \pm 0.7$ & $9.0 \pm 0.6$ & 0.139 \\
$\mathrm{P}(\mathrm{mg} / \mathrm{dl})$ & $5.6 \pm 0.7$ & $6.5 \pm 1.5$ & $<0.05$ \\
$\mathrm{eHCO}_{3}{ }^{-\mathrm{c}}(\mathrm{mEq} / \mathrm{l})$ & $21.1 \pm 2.7$ & $22.4 \pm 3.0$ & $<0.05$ \\
\hline
\end{tabular}

All data presented as mean \pm standard deviation

$D B P$ diastolic blood pressure, $S B P$ systolic blood pressure

${ }^{\mathrm{a}} \Delta$ weight $=[$ (weight before hemodialysis - weight after last hemodialysis $) /$ dry weight $] \times 100$

${ }^{\mathrm{b}} \mathrm{Ca}$ adjusted by Payne's formula (adjusted $\left.\mathrm{Ca}\right)=\mathrm{Ca}+(4-\mathrm{Alb})$

${ }^{\mathrm{c}}$ Estimated $\mathrm{HCO}_{3}{ }^{-}=\mathrm{Na}-\mathrm{Cl}-\mathrm{P}-7$
Table 3 Changes in parameters: new start group

\begin{tabular}{|c|c|c|c|}
\hline Parameter & Na-resin $(-)$ & Na-resin (+) & $p$ value \\
\hline $\mathrm{SBP}(\mathrm{mmHg})$ & $145.8 \pm 15.6$ & $145.5 \pm 15.7$ & 0.940 \\
\hline DBP (mmHg) & $76.6 \pm 8.2$ & $78.4 \pm 9.3$ & 0.627 \\
\hline$\Delta$ Weight $^{\mathrm{a}}(\%)$ & $5.0 \pm 1.3$ & $4.9 \pm 1.1$ & 0.381 \\
\hline $\mathrm{Na}(\mathrm{mEq} / \mathrm{l})$ & $137.4 \pm 2.3$ & $139.0 \pm 2.5$ & $<0.05$ \\
\hline $\mathrm{K}(\mathrm{mEq} / \mathrm{l})$ & $5.9 \pm 0.4$ & $4.7 \pm 0.6$ & $<0.05$ \\
\hline $\mathrm{Cl}(\mathrm{mEq} / \mathrm{l})$ & $102.6 \pm 2.7$ & $102.3 \pm 3.0$ & 0.430 \\
\hline $\mathrm{Ca}^{\mathrm{b}}(\mathrm{mg} / \mathrm{dl})$ & $9.1 \pm 0.7$ & $9.0 \pm 0.6$ & 0.173 \\
\hline $\mathrm{P}(\mathrm{mg} / \mathrm{dl})$ & $6.3 \pm 1.3$ & $6.5 \pm 1.2$ & 0.186 \\
\hline $\mathrm{eHCO}_{3}{ }^{-\mathrm{c}}(\mathrm{mEq} / \mathrm{l})$ & $21.5 \pm 2.4$ & $23.2 \pm 2.3$ & $<0.05$ \\
\hline
\end{tabular}

All dat presented as mean \pm standard deviation

${ }^{\mathrm{a}} \Delta$ weight $=[$ (weight before hemodialysis - weight after last hemodialysis)/dry weight $] \times 100$

${ }^{\mathrm{b}} \mathrm{Ca}$ adjusted by Payne's formula (adjusted $\left.\mathrm{Ca}\right)=\mathrm{Ca}^{+}(4-\mathrm{Alb})$

${ }^{\mathrm{c}}$ Estimated $\mathrm{HCO}_{3}{ }^{-}=\mathrm{Na}-\mathrm{Cl}-\mathrm{P}-7$ 
the new start group reported constipation but were able to continue taking Na-resin with the support of laxative agents. No patients reported being severely constipated.

\section{Discussion}

Two types of ion-exchange resins are available for the treatment of hyperkalemia in Japan: Na-resin and Ca-resin. There is a difference in cations between these agents. For example, in vitro examinations have shown that Na-resin $1000 \mathrm{mg}$ exchanges bound $\mathrm{Na}$ for $110-135 \mathrm{mg}$ of $\mathrm{K}$, whereas Ca-resin $1000 \mathrm{mg}$ exchanges bound $\mathrm{Ca}$ for 53-71 mg of K [6]. Therefore, the amount of $\mathrm{K}$ adsorbed with Na-resin is expected to be twice that with Ca-resin. As shown in Fig. 1 [7], the difference in affinity of the cation to the polystyrene sulfonic acid resin is thought to be related to this phenomenon.

As to measurements of the ions adsorbed on the resin in the stool, only one report available of in vivo study and in English have demonstrated that Na-resin $1 \mathrm{~g}$ adsorbs an average of $\mathrm{K} 0.85 \mathrm{mEq}$, and Ca-resin $1 \mathrm{~g}$ adsorbs $\mathrm{K} 0.94 \mathrm{mEq}$ [8]. In practical terms, a significant decrease in serum $\mathrm{K}$ after switching from Ca-resin to Na-resin in patients in renal failure has been reported in the Japanese literature [9-11], but no reports are available in English. Our observation period was deliberately short to exclude the influence of factors other than resin. Serum K levels significantly decreased after switching from $\mathrm{Ca}$-resin to the same amount of $\mathrm{Na}$ resin. As such, we concluded that the $\mathrm{K}$ adsorption ability of Na-resin was stronger than that of Ca-resin.

As of 2012, Na-resin is available in 52 countries, whereas Ca-resin is available in only nine, primarily Asia, including Japan. Thus, reviews of these agents may be limited.
As to the effects of Na loading induced by Na-resin, the above-mentioned Japanese papers also reported [9-11] that serum $\mathrm{Na}$ levels increased from 0.58 to $2 \%$, within the normal range, after switching from Ca-resin to Na-resin, although effects on body weight or blood pressure were not reported. Most patients receiving dialysis have oliguria or anuria. If the thirst center required to maintain homeostasis is functioning, the serum $\mathrm{Na}$ level is maintained within the normal range by drinking fluids, even in cases with Na loading. Therefore, in patients receiving dialysis, it is expected that the $\mathrm{Na}$ load would be reflected in increased weight gain and blood pressure relative to the serum $\mathrm{Na}$ concentration. However, we found no significant differences in either blood pressure or weight gain, although two patients in the new start group required additional medications for hypertension. If the antihypertensive medications had not been added, the changes in blood pressure would have been significant. At this time, the primary explanation for the lack of remarkable problems in fluid volume overload is that a relatively small amount of Na-resin was prescribed in this study. Nepal et al. [12] reported the case of a female who developed hypernatremia in the setting of excessive Na-resin administration (60 g every $6 \mathrm{~h}$ ). If more Na-resin had been administered in our cases, volume overload would have developed, leading to pulmonary edema. Therefore, when prescribing Na-resin, clinicians should be careful to prescribe an appropriate dose.

It has also been suggested that Na-resin is effective for not only hyperkalemia but also acidosis [11]. In this study, we substituted $\mathrm{eHCO}_{3}{ }^{-}$for $\mathrm{HCO}_{3}{ }^{-}$values because $\mathrm{HCO}_{3}{ }^{-}$was not often measured. The findings showed statistically significant improvements in acidosis, from $21.1 \pm 2.7$ to $22.4 \pm 3.0 \mathrm{mEq} / \mathrm{l}$ in the change group and from $21.5 \pm 2.4$ to $23.2 \pm 2.3 \mathrm{mEq} / 1$ in the new start group. Furthermore, it has been reported that the coronary artery calcification score
Fig. 1 Difference in affinity of the cation to the polystyrene sulfonic acid resin. Modified from The Japanese Pharmacopoeia [7]

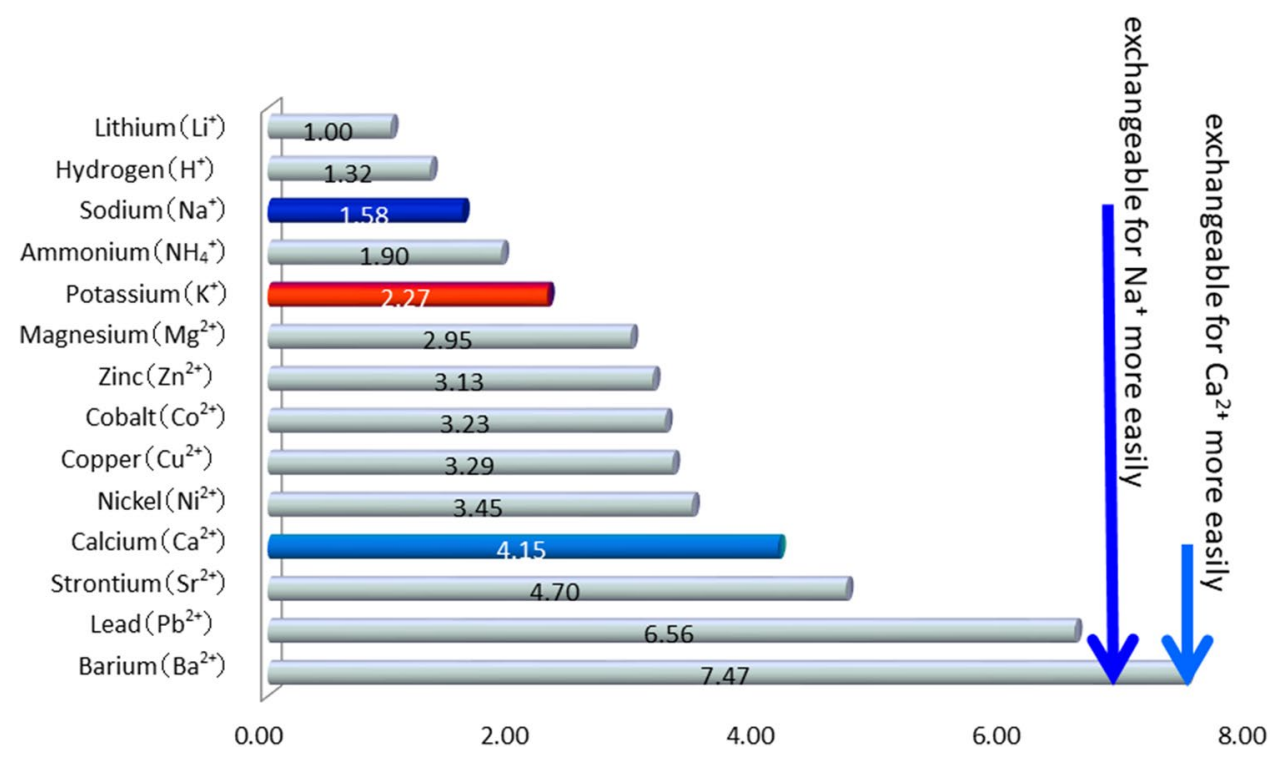


is higher when the serum pre-dialysis $\mathrm{HCO}_{3}{ }^{-}$value is low [13]. Therefore, the effect of Na-resin in improving acidosis is considered useful.

We observed no changes in serum Ca levels after switching from Ca-resin to Na-resin and limited effects of Ca loading from Ca-resin. The primary explanation for the lack of change in serum $\mathrm{Ca}$ is that a relatively small amount of $\mathrm{Ca}$ resin was prescribed in this study. An increased intake of $\mathrm{Ca}$ has also been reported to be a risk factor for vascular calcification and cardiovascular events $[14,15]$. The clinical practice guidelines for chronic kidney disease-mineral and bone disorder (CKD-MBD) recommend that intake of precipitated calcium carbonate be limited to $3 \mathrm{~g} /$ day [16] to prevent excessive $\mathrm{Ca}$ consumption. A total of $\mathrm{Ca} 350-450 \mathrm{mg}$ is included in Ca-resin $5 \mathrm{~g}$, whereas $\mathrm{Ca} 400 \mathrm{mg}$ is included in $\mathrm{CaCO}_{3} 1 \mathrm{~g}$; these values are almost equivalent. When prescribing $\mathrm{Ca}$-resin and precipitated calcium carbonate simultaneously, physicians should be careful not to prescribe too much of either compound.

Two promising new drugs have recently been developed for the treatment of hyperkalemia. One reportedly contains calcium and is nonabsorbable [2], the other contains sodium and has excellent adsorption power [3], and both are expected to have few side effects. Practical clinical evaluations of these agents will be needed in the future.

\section{Conclusion}

When using an ion-exchange resin to treat hyperkalemia in patients with chronic renal failure, the $\mathrm{K}$ adsorption ability of Na-resin is slightly stronger than that of Ca-resin. In addition, treatment with Na-resin is expected to improve acidosis. When used in small amounts (5-15 g/day), as in the present study, Na-resin exhibits an advantage in the treatment of hyperkalemia. However, when prescribing a higher dose of ion-exchange resins, physicians should select the type and amount of resin according to the $\mathrm{Na}$ and/or $\mathrm{Ca}$ load in each case. As such, if $>10 \mathrm{~g}$ of resins is needed to control hyperkalemia, combined Na-resin and Ca-resin may be necessary.

\section{Compliance with Ethical Standards}

Conflicts of interest Teruko Nakamura, Taisei Fujisaki, Motoaki Miyazono, Maki Yoshihara, Hiroshi Jinnouchi, Kenichi Fukunari, Yuki Awanami, Yuki Ikeda, Kohei Hashimoto, Masatora Yamasaki, Yasunori Nonaka, Makoto Fukuda, Tomoya Kishi, and Yuji Ikeda have no conflicts of interest.

Funding No sources of funding were used to conduct this study or prepare this manuscript.

Ethical approval All procedures performed in studies involving human participants were in accordance with the ethical standards of the insti- tutional and/or national research committee and with the 1964 Declaration of Helsinki and its later amendments or comparable ethical standards. Oral informed consent was obtained from all patients, and this study was approved by the Fujisaki Hospital Ethics Review committee.

Open Access This article is distributed under the terms of the Creative Commons Attribution-NonCommercial 4.0 International License (http://creativecommons.org/licenses/by-nc/4.0/), which permits any noncommercial use, distribution, and reproduction in any medium, provided you give appropriate credit to the original author(s) and the source, provide a link to the Creative Commons license, and indicate if changes were made.

\section{References}

1. Masakane I, Nakai S, Ogata S, et al. An overview of regular dialysis treatment in Japan (As of 31 December 2013). Ther Apher Dial. 2015;19:540-74.

2. Weir MR, Bakris GL, Bushinsky DA, et al. Patiromer in patients with kidney disease and hyperkalemia receiving RAAS inhibitors. N Engl J Med. 2015;372:211-21.

3. Packham DK, Rasmussen HS, Lavin PT, et al. Sodium zirconium cyclosilicate in hyperkalemia. N Engl J Med. 2015;372:222-31.

4. Sachie H, Shouhei N, Jong K II, Masafumi F. The estimation of bicarbonate concentration in hemodialysis patients from blood biochemical values. J Jpn Soc Dial Ther. 2010;43:919-23.

5. Payne RB, Little AJ, Williams RB, Milner JR. Interpretation of serum calcium in patients with abnormal serum proteins. Br Med J. 1973;4:643-6.

6. The Japanese Pharmacopoeia. 16th edition. Tokyo: Hirokawa Shoten; 2011. p. 1283-6.

7. Yamabe T. Ionkoukanjushi-kiso-to-ouyou. Tokyo: Kaneharashuppan; 1962.

8. Berlyne GM, Janabi K, Shaw AB, Hocken AG. Treatment of hyperkalemia with a calcium-resin. Lancet. 1966;22:169-72.

9. Tsuchida R, Yamaguchi S, Maeda K. Tousekikanja ni taishuru 2shurui no koukariumuketushoukaizenzai. In: Iyakunomon, vol. 37. Tokyo: Iyakunomonsha; 1997. p. 98-101 (in Japanese).

10. Sudou Y, Sasaki S, Suzuki N. Koukariumuketushoukaizenzai Na-resin to Ca-resin no hikaku. In Iyakunomon, vol. 37. Tokyo: Iyakunomonsha; 1997. p. 378-81. (in Japanese).

11. Mitsuo H, Kusumoto M, Asada S. Koukariumuketushou ni taisuru youionkoukanjushi no tiryoukouka. Jpn J Clin Dialysis. 2013;29:715-20 (in Japanese).

12. Nepal M, Bucaloiu ID, Norfolk ER. Hypernatremia in a patient treated with sodium polystyrene sulfonate. Int J Nephrol Renovasc Dis. 2010;3:141-3.

13. Oka M, Ohtake T, Mochida Y, et al. Correlation of coronary artery calcification with pre-hemodialysis bicarbonate levels in patients on hemodialysis. Ther Apher Dial. 2012;16:267-71.

14. Goodman WG, Goldin J, Kuizon BD, et al. Coronary-artery calcification in young adults with end-stage renal disease who are undergoing dialysis. N Engl J Med. 2000;342:1478-83.

15. Vincenzo S, Guido B, Paolo M, Ugo M, Domenico S. An update on calcium metabolism alterations and cardiovascular risk in patients with chronic kidney disease: questions, myths and facts. J Nephrol. 2013;26:456-64.

16. Akizawa $\mathrm{T}$, Hirakata $\mathrm{H}$, Tomo $\mathrm{M}$, et al. Clinical practice guideline for CKD-MBD. J Jpn Soc Dial Ther. 2012;45:301-56. 